\title{
Shape Anisotropy Effect on Spin Torque Noise in CPP-GMR Heads with a Current-Screen Layer
}

\author{
M. Shiimoto, H. Katada, K. Nakamoto, H. Hoshiya, Y. Ikeda, K. Hoshino, and N. Yoshida \\ Central Research Laboratory, Hitachi Ltd., 2880 Kozu, Odawara, Kanagawa 256-8510, Japan
}

\begin{abstract}
We analyzed the head noise in CPP-GMR heads to clarify the effect of shape anisotropy on spin-torque noise through an experiment and calculations. We fabricated two types of CPP-GMR heads with a current-screen layer (a nano-oxide layer with a confined current path), using two different track widths (50 nm and $90 \mathrm{~nm}$ ) and the same stripe height $(100 \mathrm{~nm})$. The measured and calculated noise of a 50-nm-wide-track head is larger than that of a 90-nm one when the sensing bias voltage is $120 \mathrm{mV}$ and the peak asymmetry is the same. This behavior is explained by considering that the shape anisotropy field enhances the tilt of the magnetization, especially at the edge of the track in the free layer, and that this magnetization configuration increases spin torque. Accordingly, we clarified that spin torque noise is sensitive to a head-internal field such as a shape magnetic anisotropy field, and that controlling the shape anisotropy field is important for reducing the spin-torque noise.
\end{abstract}

Key words: spin torque, CPP-GMR, spin transfer, noise, nano-oxide layer, read head, read sensor, magnetic fluctuation

\section{カレントスクリーン型 CPP-GMR ヘッドにおける スピントルクノイズの形状異方性効果}

椎本正人・片田裕之・中本一広・星屋裕之・池田悠太・星野勝美・芳田伸雄 日立製作所中央研究所，神奈川県小田原市国府津 2880 番地（广256-8510）

\section{1. はじめに}

ハードディスクドライブの高記録密度化のためには, 再生ヘッ ドのサイズの狭小化，ならびに，高出力化と低ノイズ化が必要で ある.また，高速転送の観点から，再生ヘッドの抵抗值は適当な

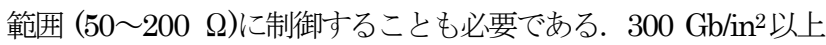
の面記録密度においては, これらの要求を満たす再生へッドの構 造として CPP-GMR (Current-Perpendicular-to-the-Plane Giant-Magnetoresistive)へッドが最も有力な候補である. CPP-GMR ヘッドには大きく分けて「オールメタル型」と 「カレントスクリーン型」の 2 つの種類がある. オールメ タル型は，スペーサー層が非磁性金属であるのに対し，カ レントスクリーン型はスペーサー層にスクリーン層と呼ば れる局所的に導電領域を有する酸化層を挿入した構成であ る. スクリーン型 CPP-GMR ヘッドではスクリーン層を最 適化することにより, 抵抗值を制御することが可能である. さらに電流狭窄効果により高い抵抗変化率（MR 比）を得 ることができる ${ }^{1-3)}$.

CPP 構造のヘッドでは，スピントルクノイズと呼ばれる 巨大な磁化摇らぎノイズが発生することが理論的にも実験 的にも知られている ${ }^{4-6)}$. 我々は, トラック幅が $80 \mathrm{~nm}$ の カレントスクリーン型, ならびに，オールメタル型ヘッド のスピントルクノイズを実測と数值計算により評価した結 果, カレントスクリーン型 CPP-GMR においては自由層と 固定層がとしてほぼ直交した状態（波形非対称性 $\pm 20 \%$ 以 内）では発生しないが，オールメタル型では直交状態にお いても発生することを報告した 7,8)。これは, オールメタル 型 CPP-GMR ヘッドでは大きな電流が流れているために,
電流磁界によって自由層磁化が不均一になっていることが 原因であることが数值計算により明らかになった。つまり, スピントルクノイズはヘッド内部の磁界に敏感であること を示唆している。そこで，ヘッド内部磁界のスピントルク に与える影響を実測と数值計算により明らかにすることを 目的として，スピントルクノイズの形状異方性依存性を研 究した結果を報告する.

\section{2. 実験及び計算方法}

我々は, カレントスクリーン型 CPP-GMR ヘッドを試作 した。スクリーン層には酸化 $\mathrm{CoFe}$ 層を用い, これを $\mathrm{Cu}$ 中間層内に挿入した。試作したヘッドのサイズを Table.1 に示す。素子高さ $(\mathrm{SH}) 100 \mathrm{~nm}$, 幾何学トラック幅(Tw) 50 $\mathrm{nm}$ の Head A と素子高さ $(\mathrm{SH}) 100 \mathrm{~nm}$, 幾何学トラック幅 (Tw） 90 の Head B の 2 種類のヘッドを試作した. 面積抵 抗（RA）は $0.25 \Omega \mu \mathrm{m}^{2}$ であり, $\mathrm{MR}$ 比は $4 \%$ である. ト ラックの両端には, 自由層を単磁区化するために, 磁区制 御膜を設けている. Fig. 1 にヘッドの磁性層の構造と磁化 方向の模式図を示す。図に示すように, 電子は固定層から 自由層へ流した。本研究においては再生出力測定とへッド ノイズ測定を行った. 測定は全てバイアス電圧 $(\mathrm{Vb})$ が 120

Table 1. Track width and stripe height for heads A, B, and $\mathrm{C}$.

\begin{tabular}{lccc}
\hline & $\begin{array}{c}\text { Head A } \\
\text { Meas. \& cal. }\end{array}$ & $\begin{array}{c}\text { Head B } \\
\text { Meas. \& cal. }\end{array}$ & $\begin{array}{c}\text { Head C } \\
\text { Cal. }\end{array}$ \\
\hline Track width $(\mathrm{nm})$ & 50 & 90 & 50 \\
\hline Stripe height $(\mathrm{nm})$ & 100 & 100 & 50 \\
\hline
\end{tabular}




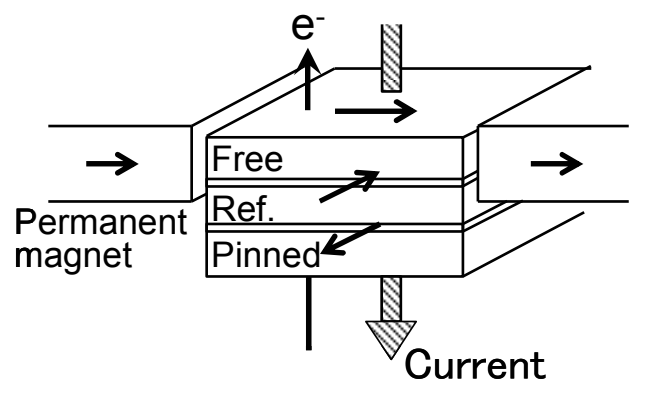

Fig. 1 Schematic figure of the magnetic layers of CPP-GMR heads.

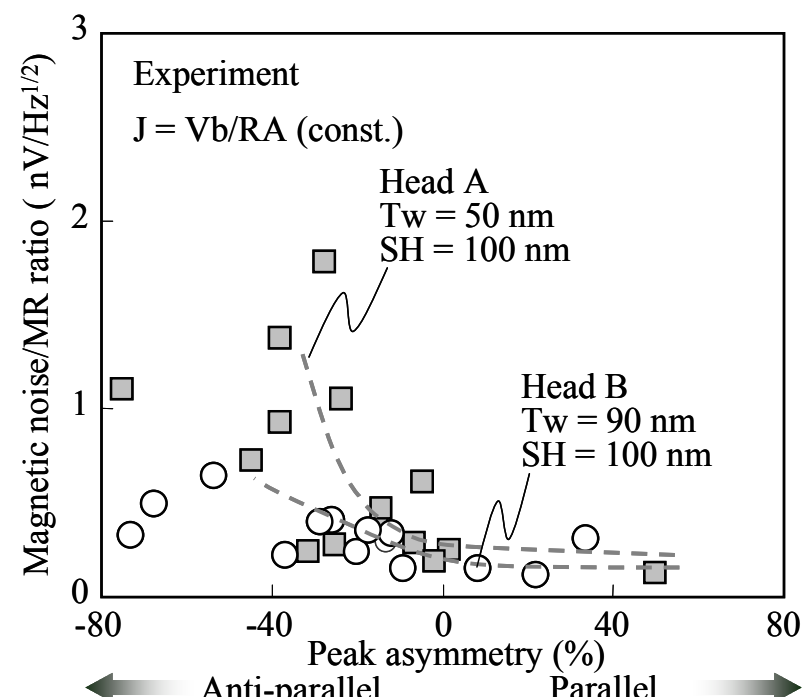

Fig. 2 Measured normalized magnetic noise vs. peak asymmetry for heads A and B.

$\mathrm{mV}$ の一定の条件において行った。ヘッドの膜全体として の電流密度 (J) は, $\mathrm{Vb}$ と RA が一定であるため, 一定值 $4.8 \times 10^{7} \mathrm{~A} / \mathrm{cm}^{2}$ である. 再生出力はヘッドの素子高さ方向 に媒体磁場相当の一様磁場を印加することで測定した。 ッドノイズスペクトラムはスペクトラムアナライザーを用 いて測定した。 スピントルクノイズやマグノイズ 9)に起因 する磁化摇らぎノイズは，実測のヘッドノイズから抵抗， イズの計算值を除去することにより求めた。 HDD の帯域 は約 $1 \mathrm{GHz}$ 以下であるので, 磁化摇らぎノイズの実測值と 計算值もこの帯域の平均值を用いた。また、磁化摇らぎノ イズは MR 比に比例するためにこれで規格化したものを議 論する.

数值計算は, スピントルクの項 10)を考慮した Landau-Lifshitz-Gilbert 方程式を用いたマイクロマグネ ティックシミュレーションにより熱やスピントルクに起因 する磁化摇らぎノイズを求めた。各磁性層は $10(\mathrm{Tw}) \times$ $10(\mathrm{SH}) \times \mathrm{t} \mathrm{nm}$ のセルに分割し計算した。分極率は 0.3 , ダ ンピングパラメータは 0.015 , 計算時間間隔は $10 \mathrm{femto}$ sec とした。

\section{3. 実験・計算結果および考察}

\subsection{1 スピントルクノイズの測定結果}

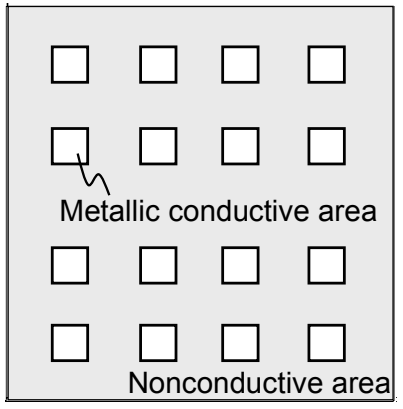

Fig. 3 Model of a current-screen layer in micromagnetic simulation.

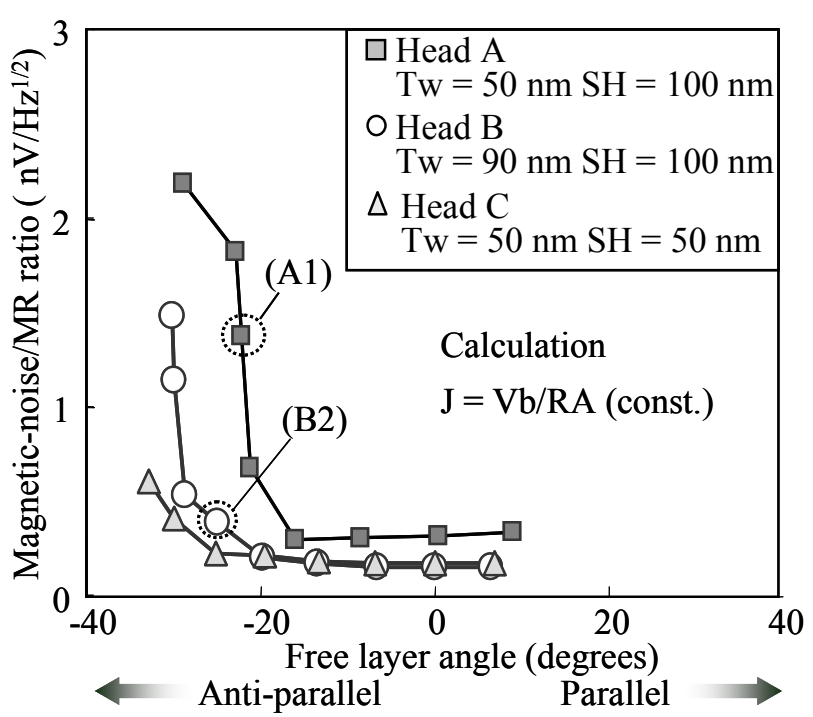

Fig. 4 Calculated normalized magnetic noise vs. free layer for heads A, B, and C.

Fig.2 に Head A と Head B の実測による規格化磁化摇ら ぎノイズと波形非対称性 (ピークアシンメトリ)の関係を示 す. 波形非対称性は, 自由層と固定層の磁化の相対角度を 反映した值であり，ゼロのときに自由層と固定層の磁化は 直交，マイナスのときに反平行方向であり，プラスのとき に平行方向である. Fig.2 から, 磁化摇らぎノイズは固定層 と自由層が反平行状態になるほど増加している。この振る 舞いは, スピントルクノイズの理論や実測の報告 ${ }^{5,7)}$ と一致 しており，スピントルクノイズの増加によるものであると 考えられる. また, Head A の磁化摇らぎノイズは, Head B よりも大きく, スピントルクノイズが大きいと考えられる.

\section{2 スピントルクノイズの自由層角度依存性}

Fig.3 に計算モデルを示す. スクリーン層による電流の絞 込みを考慮し, 伝導領域のみに電流が流れているモデルを 用いた.ヘッドのサイズは, 実測したヘッドに対応する $\mathrm{He}$ ad A と Head B に加えて, 比較のために, Head C $(\mathrm{Tw}=\mathrm{SH}=50 \mathrm{~nm})$ についても計算した. Fig.4 に磁化摇らぎ ノイズと自由層磁化角度の時間平均の計算結果を示す. 自 由層磁化角度は，スピントルクにより磁化が曲がる効果を 


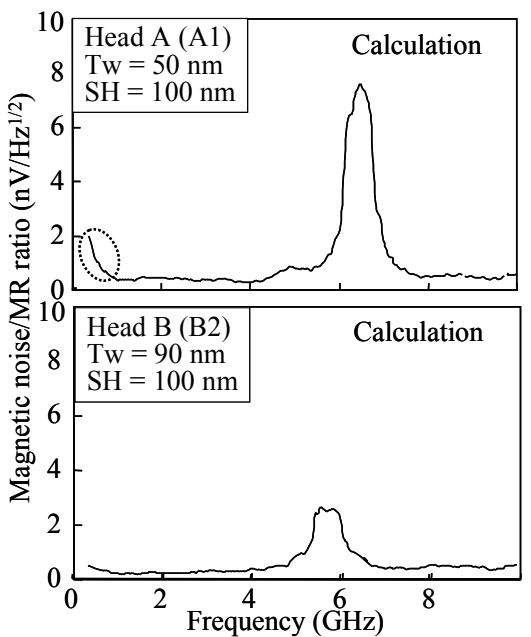

Fig. 5 Calculated magnetic noise spectra for heads A and $\mathrm{B}$ when the magnetization angle in the free layer is about 30 degrees.

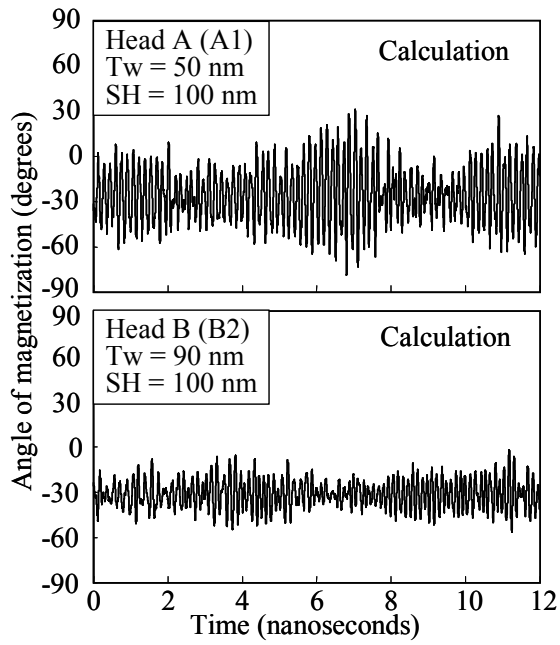

Fig. 6 Angle of magnetization in the free layer vs. time for heads $\mathrm{A}$ and $\mathrm{B}$ when the time-averaged magnetization angle in the free layer is 30 degrees.

含んでいる．自由層磁化角度はゼロのときに固定層磁化と 自由層磁化は直交と定義し，マイナスのとき反平行方向で あり，プラスのときに平行方向であると定義した．自由層 磁化角度は外部から一様磁界を印加することによって変化 させた.Fig. 4 から Head A の磁化摇らぎノイズはHead B よりも大きく，数值計算は実験結果を良く再現している. さらに, Head A の磁化摇らぎノイズは，最もサイズの小 さいHead C の磁化摇らぎノイズと比較しても大きい.こ れらの結果から，スピントルクノイズは単純なサイズ効果 ではなく，形状異方性磁界が影響していると考えられる。

\section{3 ノイズスペクトラムの比較}

Fig. 5 に Head A と Head B の自由層磁化角度が約 $-30^{\circ}$ の ときの Fig.4 に示す(A1) と（B2）におけるノイズスペクト ラムを示す. Head A ではHead B よりも大きな $1 / \mathrm{f}^{(\mathrm{n})}$ ノイ ズが発現している.よって, Fig.4 において Head A の方が 磁化摇らぎノイズが大きい原因は，巨大な $1 / \mathrm{f}^{\mathrm{n}}$ ノイズの発

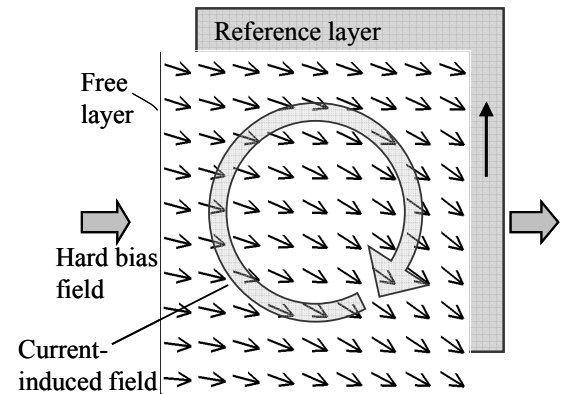

Fig. 7 Schematic figure of the magnetic layers and head-internal field.

Table 2. Calculated head-internal field for heads A and B.

\begin{tabular}{lll} 
& Head A & Head B \\
\hline Track width $(\mathrm{nm})$ & 50 & 90 \\
\hline Stripe height $(\mathrm{nm})$ & 100 & 100 \\
\hline Hard bias field in the track edge $(\mathrm{Oe})$ & 1400 & 1400 \\
\hline Current-induced field in the track edge $(\mathrm{Oe})$ & 130 & 180 \\
\hline Shape anisotropy field & Large & Small \\
\hline Stiffness field $H_{\text {stiff }}(\mathrm{Oe})$ & 300 & 400
\end{tabular}

生にあることがわかる. Fig.6 に(A1) と（B2) 状態における自 由層磁化角度の時間依存性を示す。(A1) 状態では (B2) 状態 と比較して, Fig.5（A1）中の $1 / \mathrm{f}^{\mathrm{n}}$ ノイズに対応した長周期 の大きな磁化摇らぎが発生していることが確認できる.

\section{4 自由層磁化状態の比較}

Head A の 1/f $\mathrm{f}^{\mathrm{I}}$ ノイズが, Head B よりも大きい原因を明らか にするために，ヘッド内部磁界と磁化状態を比較する. Fig.7 にヘッド内部に印加されている磁界を模式的に示す. ヘッドに は主に磁区制御磁界, 電流磁界と形状異方性磁界が印加されて いる. Table 2 に，トラック端部領域に印加されている磁界の 大きさを示す．磁区制御磁界は Head A と Head B で等しく, 電流磁界は Head B の方が約 50 Oe 大きい. 一方, 素子高さ方 向への形状異方性磁界は Head A の方が大きい. これは, Head $\mathrm{A}$ の実効的な異方性磁界 $H_{\text {stiff }}$ の大きさが, Head Bよりも約 100 Oe 小さいことからもわかる． $H_{\text {stiff }}$ とは磁区制御磁界や形状異 方性磁界などの全てのへッド内部磁界を反映した值であり 11) スピントルクがない状態におけるノイズスペクトラムの共鳴周 波数を計算することにより導出した.このため, HeadA の $H_{\text {stiff }}$ が Head Bよりも小さいのは, 素子高さ方向への形状異方性磁 界が大きいためであると考えられる.

Fig.8 に Head A と Head B のトラック端部における自由層 角度の時間依存性を示寸. Fig.8 からトラック端部において も Head A の磁化摇らぎは Head B よりも大きいことがわ る. Fig.9 に自由層磁化角度が約- $30^{\circ}$ である Head A と Head $\mathrm{B}$ の自由層の磁化状態を示す. (a) と(b)は時間平均した自由層の 磁化状態を，(c)，（d），(e)，(f)は Fig.8 に示すある時間におけ る磁化状態を示している. Fig.9 から時間平均した磁化状態 (a) と(b)は，自由層内において均一に傾いていることがわか 

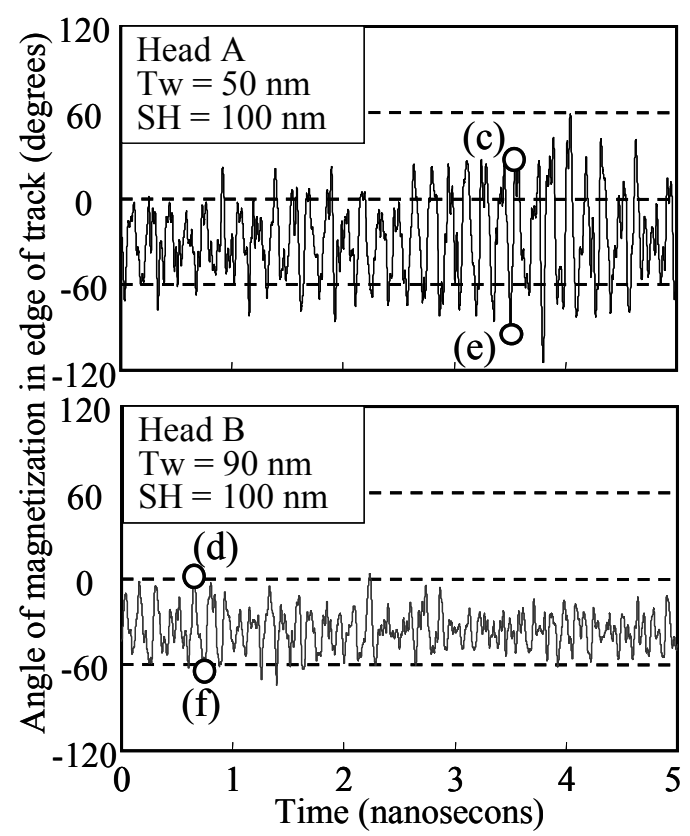

Fig. 8 Dependence of the magnetization in the free layer on time for a CPP-GMR head for heads A and B.

る. 一方, 自由層が固定層と平行方向に大きく傾いた状態 (c)と (d)では，磁化の傾きは Head A 方が大きい。 また，こ の傾向はトラック端部において特に顕著である。自由層が 固定層と反平行方向に傾いた状態(e)と(f)においても同様 に，Head A の方が磁化の傾きが大きい，これは，Head A では素子高さ方向への形状異方性磁界が大きいために, 磁 化の傾きが増加しやすいためである．また，磁化同士は磁 気的に結合しているのでトラック端部の磁化の傾きが増大 寸ると，トラック中心部の磁化も大きく傾く．このように して, 形状異方性磁界により磁化が大きく傾き，スピント ルクノイズが増大寸ると考えられる。したがって，スピン トルクノイズの抑制には形状異方性磁界などのへッド内部 磁界の制御が重要である。

\section{4 まとめ}

ヘッド内部磁界がスピントルクノイズに与える影響を明 らかにするために, 形状異方性磁界が異なる 2 種類のカレ ントスクリーン型 CPP-GMR ヘッドのスピントルクノイズ を実測と数值計算により評価した結果，(1)素子高さ方向に 形状異方性が大きいヘッドの方がスピントルクノイズは大 きいこと(2)これは形状異方性磁界が特にトラック幅端部に おける磁化の傾きを増加させることにより，スピントルク ノイズによって $1 / \mathrm{f}^{(\mathrm{n})}$ ノイズが増加すること (3)スピントルク ノイズはヘッド内部磁界に敏感であること,の結論を得た。 これらの結論より，スピントルクノイズを低減するために は, 従来から知られている電流方向や自由層と固定層の相 対角度の制御と共に, 形状異方性磁界に代表されるへッド 内部磁界の制御も重要であることが明らかになった。

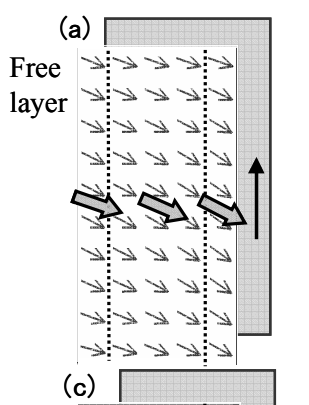

(b) Reference layer

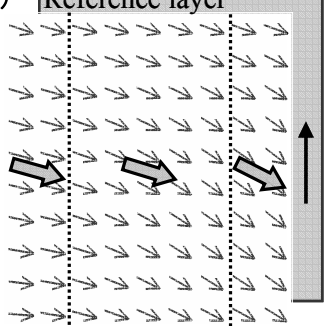

Free $1 \mathrm{i} \rightarrow \rightarrow \rightarrow$

layer $\rightarrow \rightarrow \rightarrow$ $\lambda \rightarrow \rightarrow$ $\rightarrow \rightarrow \rightarrow$

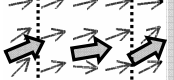
$\rightarrow \rightarrow \rightarrow \rightarrow$ $\rightarrow \rightarrow \rightarrow \rightarrow$ $\lambda: \rightarrow \rightarrow$ $\lambda \rightarrow \rightarrow \searrow$

(e)

Free $\downarrow \vdots y \searrow>$

layer

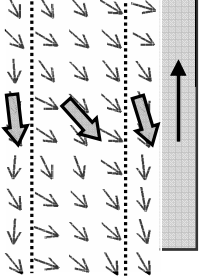

(d) Reference layer

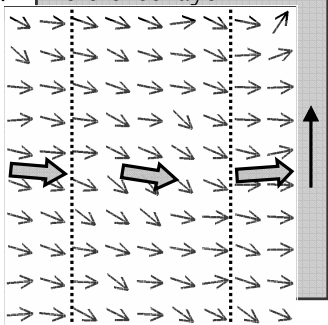

(f) Reference layer

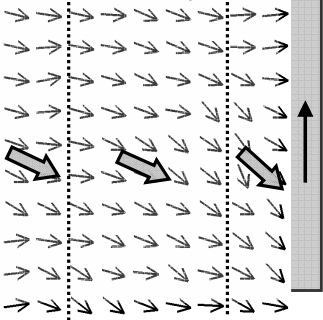

Fig. 9 Time-averaged (a), (b) and momentary (c), (d), (e), and (f) magnetization configurations of the free layer for heads $\mathrm{A}$ and $\mathrm{B}$.

謝辞 日立製作所の目黒賢一氏，渡邊克朗氏，安井感氏， 高澤浩幸氏，田中秀明氏，難波明博氏，日立グローバルス トレージテクノロジーズの N. Smith 氏, J. Childress 氏, には本研究を行うにあたり多大のご協力を頂きました。ご 協力頂いた方に深く感謝致します.

\section{References}

1) K. Nagasaka, Y. Seyama, L. Varga, Y. Shimizu, and A. Tanaka: J. Appl. Phys., 89, 6943 (2001).

2) H. Fukuzawa, H. Yuasa, S, Hashimoto, K. Koi, H. Iwasaki, M. Takagishi, Y. Tanaka, and M. Sahashi: IEEE. Trans. Magn., 40, 2236 (2002).

3) K. Hoshino, H. Hoshiya, H. Katada, N. Yoshida, K. Watanabe, and K. Nakamoto: IEEE Trans. Magn., 41. 2926 (2005).

4) M. Covington, M. AlHajDarwish, Y. Ding, N. J. Gokemeijer, and M. A. Seigler: Phys. Rev. B, 69, 184406-1 (2004).

5) J. G. Zhu and X. Zhu: IEEE Trans. Magn., 40, 182 (2004).

6) N. Smith, J. A. Katine, J. R. Childress, and M. J. Carey: IEEE Trans. Magn., 41, 2935 (2005).

7) H. Katada, K. Nakamoto, H. Hoshiya, K. Hoshino, and N. Yoshida, IEEE Trans. Magn., 42, 2450 (2006).

8) H. Katada, M. Shiimoto, K. Nakamoto, H. Hoshiya, K. Hoshino, and N. Yoshida, J. Magn. Soc. Jpn., 31, 31 ( 2007).

9) N. Smith and P. Arnett: Appl. Phys. Lett., 781448 (2001). 10) J. C. Slonczewski, J. Magn. Magn. Mater., 159, L1 (1996).

11) K. B. Klaassen, X. Xing and J. C. L. Peppen: IEEE Trans. Magn., 41. 2307 (2005).

2007年10月4日受理，2008年1月9日採録 